\title{
Voz e arquivo: Eleonora Fabião, Ricardo Chacal e Ricardo Domeneck
}

Resumo: A voz, em contato com o arquivo, empresta ao texto o som da poesia. Assim, o consumo do arquivo pela voz não reconhece limites entre o fato e o poético. Ao mesmo tempo em que tal empréstimo se dá, também se dá uma tomada inadvertida. A voz se apossa do arquivo para recolocá-lo em cena. Transforma a materialidade gráfica em materialidade sonora, o código em ambiente. Rouba o dizer apenas por um momento. Logo em seguida, recusa a posse e segue adiante. Assim são as vozes de Eleonora Fabião, Ricardo Chacal e Ricardo Domeneck. É a partir dessas dinâmicas da leitura deles que observamos como a voz oferece sua vibração à escuta. Então, o poema é e não é uma informação. É e não é o exercício de autoria. Nesse jogo entre arquivo e repertório (Taylor 2013), o poema é uma performance em comunhão que, presente de corpo a corpo, sobrepõe temporalidades. Corta o passado no ato presente. Torna o arquivo uma moenda do tempo histórico.

Palavras-chave: voz, poesia, arquivo, leitura, performance

Abstract: The voice in contact with the archive lends the sound of poetry to the text. Thus the consumption of the archive by the voice does not recognize the limits between the fact and the poetic. At the same time that such a loan takes place, an inadvertent borrowing also takes place from it. The voice takes possession of the archive to put it back on stage. It transforms graphic materiality into sound materiality. The voice steals their dictates just for an instant. Soon after, the voice refuses its possession and moves on. There are the voices of Eleonora Fabião, Ricardo Chacal and Ricardo Domeneck. It is from these dynamics of their reading that we observe how the voice offers its vibration to listening. So the poem it is and it is not simply information. It is and it is not an exercise of authorship. In this game between archive and repertoire (Taylor 2013), the poem is a communion that, present from body to body, overlaps temporalities. It makes the past resonate within the present. Makes the archive a mill of historical time.

Keywords: voice, poetry, archive, reading, performance 


\section{Introdução}

Quando propomos pensar a leitura de poesia nos termos de um consumo do arquivo pela voz, damos muitos passos na direção da poesia como um acontecimento da performance. Se também nos concentramos na sonoridade da voz, percebemos o uso do arquivo sendo decidido numa atividade errante e ritual de multi encenação do texto. $\mathrm{E}$ basta a presença da voz para sua forma absorver a trama do poema. A voz não requer a poesia, ela é, em sua própria medida, um "fato poético" (Zumthor 2018: 73); isto é, veremos aqui como a voz anuncia a linguagem alicerçada apenas em poeticidade. 0 que nos importa é mensurar (e desmensurar) como sua mera enunciação alarga os caminhos de interpretação do texto para além da imaginação da escrita como força visual (Cavarero 2011). O som da voz é inefável e mutante. Por isso, a literatura também assim é.

E a imposição da voz não dá margem. Na leitura, a voz se inteira do arquivo. É voraz, única e autoritária; ao mesmo tempo que breve, insinuante e persuasiva. A voz consome o arquivo para abandoná-lo, vocacionada em deixar indícios e não contraprovas. Assim também ela reclama e estressa. Pela fresta invisível do som, toma o poema e, nele, se afigura. A possessão é, na melhor medida, uma materialidade fundida de corpo e poesia, de texto e contexto (Glusberg 1986). A leitura ganha a estrutura de seu consumo, cai pela garganta e vibra pelo ambiente. E é uma coisa feita para se fazer de novo. Em cada revisita da voz, as temporalidades do arquivo - sua insistência em durar - se sobrepõem no mesmo gesto vocal (Bernstein 2009), repetidas vezes, enquanto acessível. Nessa armação do som da poesia, ironicamente, "a soberania da linguagem se rende à soberania da voz" (Cavarero 2011: 25).

A partir dessa janela de contato do sonoro com o gráfico, desenhamos um breve exercício crítico que posiciona texto e voz em duplo-ataque ao sentido do poema nas performances de Eleonora Fabião, Ricardo Chacal e Ricardo Domeneck, com a ajuda de Diana Taylor e de Charles Bernstein.

\section{Encanto eletrônico}

Durante os primeiros meses da quarentena para frear o contágio pelo novo coronavírus, a Escola de Arte Dramática da USP organizou uma série de falas no programa Perspectivas Anos 20. A atividade foi realizada por videoconferência, pela plataforma Zoom; uma maneira possível de seguir as atividades acadêmicas uma vez que aglomerações de pessoas em lugares fechados é uma das principais vias de disseminação do coronavírus - um dos muitos comportamentos que precisaram ser evitados para que se reduzisse os casos da infecção covid-19; uma doença atroz que, principalmente, acomete e destrói os pulmões, fazendo com que os enfermos graves morram por asfixia.

Uma das convidadas do programa foi Eleonora Fabião, que apresentou uma ação concebida especialmente para acontecer por videoconferência, o Eletrovento (2020). ${ }^{1} \mathrm{~A}$ pandemia em curso está dando os moldes de uma crise sanitária sem precedentes, agravando decisivamente a situação política e econômica que temos enfrentado nos últimos 
anos no Brasil - e o mais aterrorizante, fazendo aflorar questões delicadas de nosso cotidiano; em que se pese a maneira como historicamente nossos costumes refletem sobre a morte, o desaparecimento, a chacina e o genocídio. ${ }^{2}$ Com o seu Eletrovento, Fabião intenciona uma posição frente a frente com este tempo político incontornável (e aparentemente insuperável). Ela cria uma espécie de máquina do destino que dialoga com seus próprios processos sistemáticos de eliminação.

Mover a máquina dedicada a "continuar a fazer do planeta um inferno, conforme no Brasil estamos assistindo", como Milton Santos (2021: 19) bem criticou, demanda uma ação de revisita aos bolsões de dor que permeiam a vida pública no país - fatos e situações que precisam ser reafirmados para que se tornem visíveis, aparentes, opacos, quando anunciados pelo choque de consciência e pelo abalo emocional contidos nos recados da voz (Zular 2020). Fabião mobiliza o sistema Eletrovento imergindo-o nesse som: ela conta, reconta, lê, relê; soma-se nas sucessões de violências cíclicas e nos reconhecimentos do terror, pois esse tipo trauma, nos segreda Diana Taylor (2009: 7), "é conhecido por sua natureza de repetição. Ele nunca acontece pela primeira vez". Fabião fala o que aconteceu para que entendamos: ainda está acontecendo. O Brasil matou. 0 Brasil está matando.

A situação planejada parece partir de uma reação ao inferno de Milton Santos. No Eletrovento, a dinâmica é: Eleonora Fabião apresenta aos participantes na sala virtual um leque de cartas e pede para que cada um/a faça uma escolha, que diga a ela qual carta deve ser acionada. Cada carta resguarda uma ativação. Uma vez escolhida, ela revela o conteúdo (um título, uma frase, uma palavra) que desencadeia, por três a cinco minutos, uma ação. Ela alterna sua fala entre trechos de livros, como Encantamento, de Luiz Antonio Simas e Luiz Rufino (2020), “O feminismo não é um humanismo”, de Paul Preciado ou A queda do céu, de David Kopenawa e Bruce Albert (2015); registros de performances elaboradas por ela recentemente como a ação M.E.S.A. e Levante; entre outros arquivos de texto, fotos e vídeos. Na sua tela, Fabião está sentada em uma mesa, ao lado de um vaso com uma espada-de-são-jorge e, na parede, duas linhas cor magenta compõe o plano.

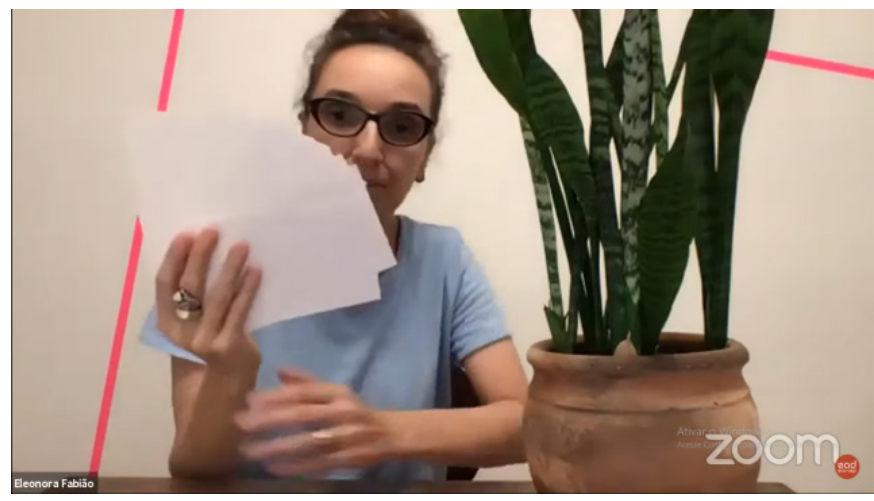




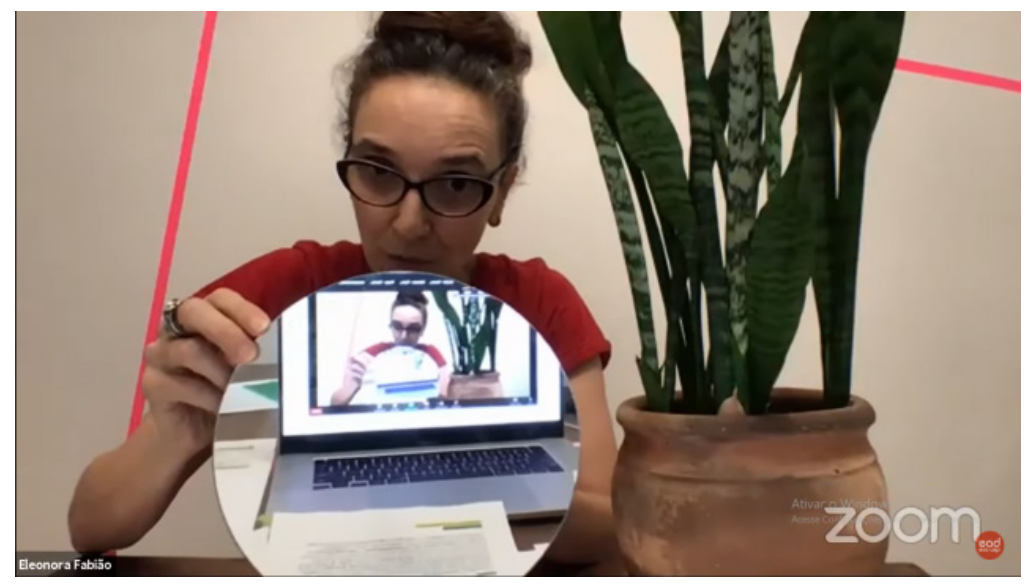

Figura 1: Dois frames da performance Eletrovento, de Eleonora Fabião (2020), realizada na plataforma de videoconferência Zoom. De camisa azul, ela mostra o leque de cartas para a escolha do/a participante; de camisa vermelha, reflete o plano por trás da câmera do computador com o apoio de um espelho; depois, direciona-o de frente para a tela. Escola de Arte Dramática da USP, São Paulo, 2020. Disponível em https://youtu.be/8dELALbpsjs. Acesso em 27/07/2021.

A cada pedido por uma carta, uma escada é composta por sua narrativa. Uma vez revelada, a carta passa então a reger a cena. Uma série de gestos responde às propostas. Articulações entre dizer e fazer que são construídas por dentro da videoconferência, valendo-se inclusive de suas ferramentas, como o compartilhamento de tela para exibir um vídeo ou uma foto, e da própria imagem em transmissão - quando Fabião lê um trecho de $A$ queda do céu, por exemplo, um plástico semi translúcido é colocado por ela em sua câmera, tendo assim a imagem alterada por um filtro verde, um verde imersivo que se torna, a partir dali, seu ambiente. A leitura das palavras de um xamã ianomâmi se dá então por uma imersão no verde, uma imersão na floresta. Se, no início, ela está de camisa azul, dado momento a retira e, por baixo, surge a camisa vermelha. Fabião elaborou Eletrovento em correspondência às cores do padrão RGB (red green blue) utilizado pelas telas de vídeo, em que vermelho, verde e azul são as cores primárias que dão origem a todas as outras. As cores estão vestidas por ela, marcadas pelos objetos em cena e, mais além, na própria expansão da lógica visual do vídeo, transformando sua performance num tipo de alegoria analógica de uma vibração eletrônica, cada vez mais determinante na visualidade cotidiana mediada por telas - situação que, durante as quarentenas e o período de isolamento social, tornou-se exponencialmente mais incidente.

As cartas fazem então este cenário se mover. Como se estivessem preparadas para vir aos olhos apenas depois de a sorte ser lançada na roleta russa da intuição. As escoIhas apontadas pelos/as participantes interferem no ritmo das cenas, e constroem naquele momento uma narrativa elabora pela exposição dos fragmentos. Cada carta refaz 
a "gira", como disse o professor José Fernando Peixoto de Azevedo ao comentar sobre o que havia acabado de viver durante a sessão. Os fragmentos só aparecem quando o acaso conspira a favor, então, mostram-se na segurança de sua revelação; é este o momento em que Fabião faz suas emersões, exibindo-se sempre após uma convocação.

Suas reações também guardam, curiosamente, uma resposta à carta revelada. A exibição pode vir por qualquer lado, rompendo a sensação do sufocamento do espaço que o cansativo quadradinho do Zoom causa a quem está recebendo a transmissão; ela usa o espelho para explorar objetos por trás da câmera de seu computador, deixando-nos ver aos poucos a totalidade do cenário em que a videoconferência está acontecendo - são as partes não vistas, mostradas por ela de objeto a objeto, que parecem propor uma elucidação do que é ignorado pela câmera. Assim ela nos ensina a ler os textos que convoca: rodopia o discurso pelo abraço do arredor. Será que estamos vendo tudo o que está acontecendo quando lemos um texto?

Quando a carta "voz" é escolhida, ela executa a gravação da canção "O sol nascerá", de Nelson Cavaquinho, na interpretação de Elza Soares. Se há uma voz, essa voz é de uma mulher negra, uma voz que sacramenta um "juízo final”, uma voz do samba. Aos poucos, seus movimentos fragmentados vão jogando fagulhas em uma estética vertida em uma política da atuação, como ela diz, "as artes da cena tem muitas possibilidades". Fabião cria, então, uma maneira possível de jogar com o destino que estamos indubitavelmente compartilhando, vivendo junto, através de armações desenvolvidas em resposta ao convívio na violência - especula-se ali o curso de um destino forjado pela sequência de violações. A performance então nos devolve, pelo seu fazer, um ambiente de contato com quem somos agora e com quem podemos ser depois. Esse exercício nos reflete em uma atividade continuada, cujo engajamento do corpo na ação da performance cria um amplo campo de mobilização das sensibilidades, em que "a possibilidade de troca, crítica e criatividade dentro da repetição" (Taylor 2012: 8) deforma os costumes sociais para dizer outra coisa.

\section{A voz vira outra coisa}

O anúncio da ação de Fabião guarda um procedimento de revelação. Ela também constrói seus sentidos em torno da instrução versada pela carta, um título para o gesto. Essa situação de regência do ato pela semântica do próprio ato pode também ser medida por outro trabalho que, lateralmente, parece também investigar esse interesse. Isso se assemelha com o pensamento de corpo movido por Ricardo Chacal na performance Os bichos. Nela, ele apresenta uma placa com o enunciado de um personagem-animal que virá à cena, como o Alce Triste, o primeiro a ser criado e o mais icônico deles, para em seguida interpretá-lo em gestos, bem humorados e desengonçados, que fazem Chacal se mexer pela imitação dos animais.

As idas e vindas nas tentativas do corpo se entender começam a se cruzar. Na videoconferência Perspectivas Anos 20, a última carta revelada por Fabião foi "animalismo", 
um termo elaborado pelo pensamento feminista de Paul Preciado que propõe uma virada das maneiras de reiterar os corpos humanos pela negação do "humanismo" - criticado por ele como uma ficção de poder justificada historicamente por brancos heterossexuais. ${ }^{3}$ Para colocar em cena o texto puxado pela carta, Fabião pinga um corante verde em sua língua, mostra-a pintada, lambendo o ar e esticando-a, ostentando seu traço pontiagudo, como se estivesse apontando para uma mudança na substância de seu corpo que fosse capaz de aludir o "animalismo" de Preciado. A língua verde, a língua de uma fera.

Em seus gestos, Fabião parece experimentar uma situação que se descola (ou no limite de se descolar) de um espaço-tempo que, desde a colonização, funciona no Brasil como regência da vida. Uma interrupção que age por um instante. Ela parece provocar a ideia de que o pensamento do corpo é a maneira do corpo pensar, dedicando-se a movimentos que expressam um tipo de "pensamento que só o corpo é capaz", como ensina Ricardo Aleixo (2015). Pensar seus gestos é, pois, pensar a sua condição. Quando relata sobre a elaboração d'Os bichos, Chacal (2014: 6) faz uma crítica interessante sobre a sua atividade de poeta quando, para ele, depois de 40 anos, "ir ao microfone" e falar um poema se tornou "previsível". Sua saída pela imitação dos animais, pela mímica dos gestos dos bichos, pelo silêncio da sua voz (de sua expressão), coloca aquele marginal em uma elaboração de cena em negativo de suas práticas costumeiras: a voz que formou seus acentos, suas intenções de dizer e afirmar, seus desaforos assertivos, parece não encontrar mais lugar em seu corpo emissor. O trabalho ficou mudo, sem voz, sem fala - o corpo foi reprogramado para falar como uma máquina de tirar cópias gestuais. Ainda assim na comicidade, pela palavra que faz Chacal se mexer -, estão lá suas características mais marcantes que o destacaram como poeta: o deboche e a curtição. ${ }^{4}$

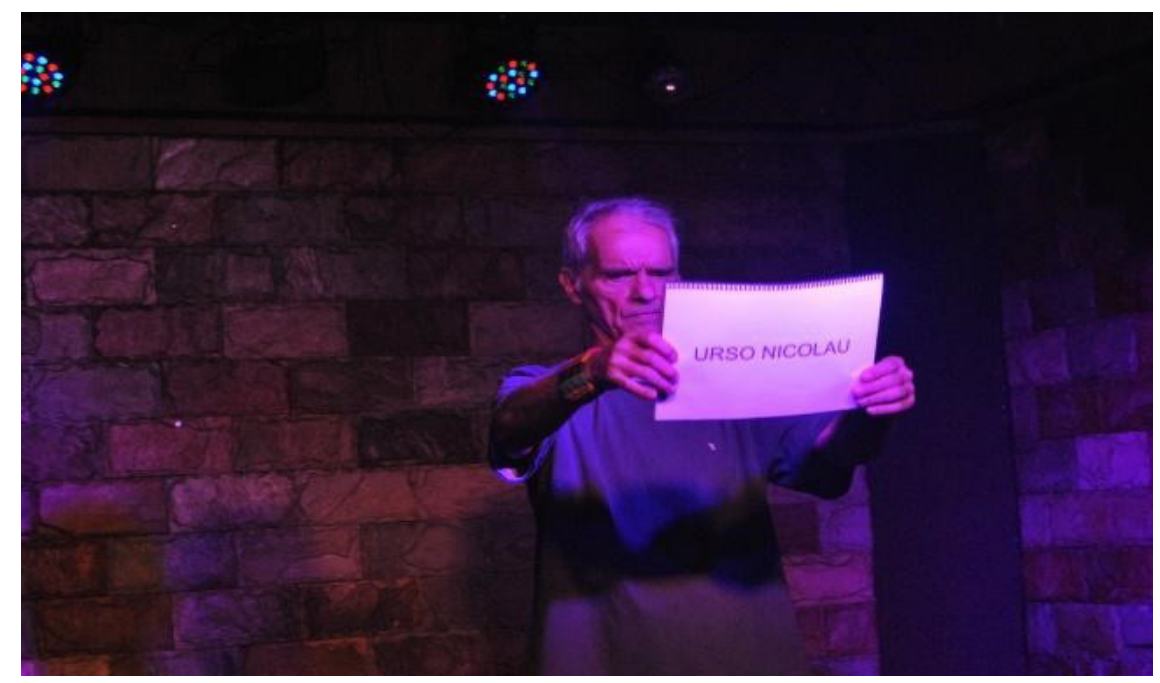




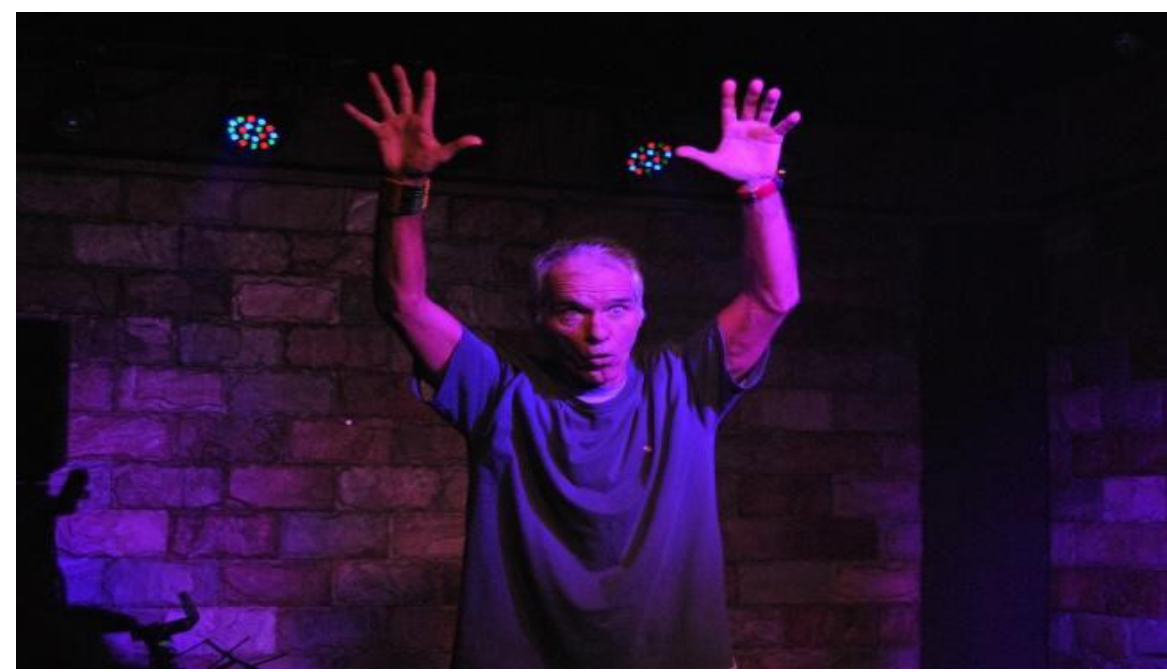

Figura 2: Chacal, acima, mostra a placa que abre a encenação do Urso Nicolau, abaixo, exibe um de seus gestos, na apresentação de Os bichos, numa exibição no programa Subcena, Audio Rebel, Rio de Janeiro, 2018. A performance foi realizada juntamente com Barrão, criador do som, uma trilha animada e descontraída que deu ritmo à cena.

Chacal e Fabião parecem propor, de maneiras distintas, uma re-humanidade pela investigação dos bichos - uma empatia construída pela interpretação da animalia, a partir de como suas necessidades demandam uma desconstitucionalização, reformando e moendo o jeito que se toca as coisas e se faz presente. Esses arquivos funcionam, portanto, para transformar. Ao lê-los, entramos dentro. Essa entrada parece requerer o corpo para mostrá-lo vivo, para mostrá-lo encantado (Simas e Rufino 2020), e condutor de sua contra história.

Por aí há mais que um procedimento útil, pois a mobilização se deforma na variação ontológica (Zular 2019): proposições insistentes de reassimilação dos marcos políticos e dos valores universais. As ligações dessa insistência com a materialidade das coisas desestabiliza o tempo histórico, pois a poética das performances emparelham, na expertise de sua viragem, marcos historicamente simultâneos nas possíveis ficções das relações entre espécies (Haraway, 2016). A poesia dos bichos é possivelmente a poesia primordial, não racional, não acadêmica, não profissional - jorrando de dentro de um Brasil que não existe. É pelo destrave do arquétipo drummondiano da máquina do mundo que a "precariedade" (Fabião 2011) da vida passa a reger seus próprios caminhos e decisões. Um corpo humano é um corpo sem governo. Logo, há nesse tipo de provocação da performance um empuxo para que o corpo passivo transite para o corpo que reage.

Essa confusão temporal chacoalha os marcos históricos porque é tão momentânea quanto, se quisermos dizer, milenar. A conta de tempo, se depender do corpo, parece não querer ser feita. Isso pode nos levar a uma interpretação crítica que se perde na infinitude. 
Se em algum momento tentarmos nos questionar, por exemplo, sobre a origem da performance, nos embaralhamos completamente no elo que, hipoteticamente, possa ser apontado como fato decisivo por ter colocado o humano em cena. "A performance em poesia é tão antiga quanto a própria poesia”, diz ironicamente Charles Bernstein (1998: 3), em seu jeito particular de desviar de questionamentos que giram em torno da gênese do poético. Não é isso que está em jogo.

Estamos propondo contornos a um corpo que se torna então a possibilidade do corpo no tempo. Um dos ganchos de Fabião sobre a "precariedade" diz também sobre o desafio de entendê-la, a auto exigência de deixá-la agir. É por isso que a continuidade da atividade da performance é uma agenda indissociável do trabalho de "inventar (...) novos corpos" (Fabião 2011: 66), que só se pretende realizável pela refundação de si e, consequentemente, do entorno. $\mathrm{E}$ isso, aqui, se dá dramaticamente no risco da leitura ou seja, quando lidamos diretamente com a materialidade de seu espírito transformador que volta à cena e suspende o instante.

Em um de seus artigos mais cintilantes, Fabião (2011) nos apresenta a noção de "precariedade" a partir dos escritos de Lygia Clark que, em sua trajetória, refletiu repetidas vezes sobre a questão de como aliar seu trabalho ao "movimento permanente" (Clark apud Fabião 2011: 63) que suas criações passaram a demandar de sua própria vida. A proximidade da precariedade foi desmembrada em atividades arte-terapêuticas de Clark como um dos nortes fundantes da Estruturação do Self (1978-1988). Uma proposta de obra em uso que executa um "programa psicofísico" com efeitos de reequilibrar o corpo (sua durabilidade material e sua composição no espaço) de seus desdobramentos comportamentais e de costumes, políticos e éticos, econômicos e sociais etc. O mundo, então, convergia ali em uma só usina de reprocessamento de si. A proposta de Clark provocava o/a participante a se conhecer pela primeira vez através de um corte no eu. A precariedade age, conduz, efetiva, assume assim uma possível vereda de transformação, um recurso que tangencia as automatizações. Diz Fabião (2011: 66, grifo meu) quando propõe sua visão sobre a performance como prática da precariedade:

Performances são elogios ao precário porque desestabilizam mecânicas comportamentais, rotinas cognitivas e hábitos de valoração; porque desfixam sentido e desmontam convenções; porque inventam, através da execução de programas psicofísicos, novos corpos, novas possibilidades de encontros, agrupamentos e devires. Performances são elogio ao precário porque suspendem o estabelecido. 0 trabalho do performer é revelar e valorizar a precariedade emancipadora do vivo. Precariedade que, no corpo performativo, deixa de ser uma condição lamentável do que está irremediavelmente condenado ao tempo, para se revelar como potência. Pois o performer investe na potência vital da precariedade, na condição de instabilidade, relatividade e indefinição em favor da permanente renovação de si, do meio e da arte. Graças à sagacidade conceitual e à dimensão política de seus atos, o pacto do performer com o precário não leva à deterioração, mas à recriação. Esta é justamente a manobra filosófica, poética e política em questão. 
Para ela a precariedade se torna condutora de sua perspectiva de que propor performances é um caminho para "mover-se permanentemente no movimento permanente" (Fabião 2011: 64). Esse vetor de incidência desestabilizada faz da performance um atividade aguda de deslocamento espaço-temporal, é a partir dessa base que o uso do arquivo passa a vibrar em regimes alterados de contato e recepção. Essa suspensão está operante quando nos voltamos para Eletrovento especialmente para observar como os arquivos são requisitados a significar a alteração pretendida. Se nos concentramos nos textos, a leitura de Fabião os recupera de seus estados de latência (do livro industrializado aos equipamentos digitais em que repousam) para dar-lhes movimento. Os textos são ações, informação que, uma vez decodificadas, são reconduzidas pela voz em sua mudança de plano, adentram as dimensões do agora e do aqui, e convivem na performance sob a regência da alteração (Zumthor 2018).

$\mathrm{Na}$ atividade Perspectivas Anos 20, a reação dos presentes ao fim de Eletrovento nos entrega facilmente o espanto que acabaram de sentir. As expressões eram de surpresa e alegria, de fascínio e, no bom sentido, ilusão. A suspensão chegou aos participantes da videoconferência. Fabião nos dá ali algumas pistas do que estamos tentando provocar, talvez nos seja importante pensar como a voz absorve um dado para, ela mesma, lidar com suas próprias aspirações mutantes. Porque aí o texto nunca é algo feito de tipos cravados. E, para alcançá-los no som, a voz precisa consumi-los. A ambiência pela via sonora é base para a investida do corpo. Para afirmá-lo no discurso corrente, como faz Fabião, ou para se esquivar de uma expectativa, como faz Chacal. As intenções de consumo do arquivo passam, então, a irromper a "unidade metafísica" (visão relacional que muitos conferem ao documento), para se manifestar como um "evento plural”, pois desse modo diz Charles Bernstein (1998: 14):

Um poema compreendido como um evento performativo e não meramente como uma entidade textual recusa a originalidade do texto escrito em favor do "evento plural" da obra, para usar uma expressão de Andrew Benjamin. Isto é, a obra não é idêntica a nenhuma realização gráfica ou performática, nem pode ser equacionada em uma unidade totalizante dessas versões ou manifestações. O poema, visto nos termos de suas múltiplas performances ou de uma intertradutibilidade mútua, tem uma existência fundamentalmente plural. Isso ganha maior dramaticidade enunciativa quando instâncias da obra se revelam contraditórias ou incomensuráveis, mas também se aplica quando as versões diversas são comensuráveis. Falar do poema em performance é, portanto, superar a ideia do poema como um objeto linguístico fixo, estável, finito; é negar no poema sua essência e unidade. Logo, quando a performance enfatiza a presença material do poema, e do performer, ao mesmo tempo nega sua presença unitária, o que quer dizer sua unidade metafísica. 


\section{Repetir a política}

O "evento performativo" de que fala Bernstein é também um portal de experimentos aberto pela durabilidade dos textos. Isso tem muito a ver com que Ricardo Domeneck (2009: s/p) trabalha na voz em suas leituras, do que ele chama de "poesia tesa", prática que não arregimenta distinções para uma hierarquização das mídias de poesia. Por consequência, voltam à prática para uma operação que habilita a voz como senso criativo a construir a oralidade e a escrita. Na poesia tesa, a voz se deixa perceber a partir do mesmo exercício que quer tornar a escrita, voz, assim como a voz, escrita.

Esta é também uma saída crítica de um poeta que, em sua formação, lidou com as tradições líricas e as contratradições concretas com igual interesse, sem abrir mão, no entanto, de uma posição ulterior. Em seu exercício, ele não quer se alinhar em procedimentos de recusa, mas sim de absorção. Está ao mesmo tempo distante de uma oralidade que entrega clichês do fetiche vanguardista assim como de um poema que não cabe na boca, déficit de uma escrita (e de um corpo) que não se permite armar pela oralidade. Contudo, está interessado em procedimentos que mantêm desafiadora uma comunicação vocal forte o bastante para se sustentar um texto. Como diz Domeneck (2009: s/p),

Em meu trabalho pessoal, meditar sobre a oralidade é um desdobramento que eu vejo como coerente com a pesquisa que se dá também em minha escritura. Em minha busca por uma relação mais saudável com as dicotomias que herdamos de certo Ocidente, com sua separação violenta entre corpo e mente, matéria e espírito, sem mencionar outras (para não exagerar na polêmica), sempre busquei, em minha escrita e a partir de minha est-É-tica, que minhas imagens, metáforas, metonímias, símiles viessem de meu corpo, do corpo humano. Queria, como nos últimos versos do poema de exórdio do meu trabalho, o primeiro da Carta aos anfíbios, escrever "como uma garganta / enrijece-se rápida / para resistir à faca".

Garganta é um termo que surge no trabalho de Domeneck para revelar uma particularidade da produção poética pensada no e para o corpo. Seja em Garganta com texto (2007), ${ }^{5}$ um vídeo-performance que contém um tipo de manifesto de uma poesia antiliteratura, que se concentra em elidir a cultura gráfica por uma voz que insistentemente não se deixa afogar (mesmo que vencida no fim), seja no título de um de seus livros Som: Arranjo: Garganta (2009). A garganta é aqui uma parte de corpo cuja vitalidade frágil é sempre postulada pelo assassínio, da mesma maneira como é a cavidade que guarda o aparelho fônico, que emite palavras a partir da despressurização atmosférica, e que pode se enrijecer ficcionalmente contra as agressões. Além, a garganta é o istmo entre a cabeça e o restante do corpo, vista como parte especialmente sensível da racionalidade manifesta, que também é revelada pela sedução, pelo erotismo (tanto da voz, quanto do cangote). A maneira como esses atributos aparecem no fazer-poesia de Domeneck jogam o espírito materialmente revelado numa "canção da carnalidade", como diz Gustavo Silveira Ribeiro (2020: 47), que ressoa pela vontade, desejo, ambição, em boa parte de seu conjunto de poemas que podem vir à cena. 

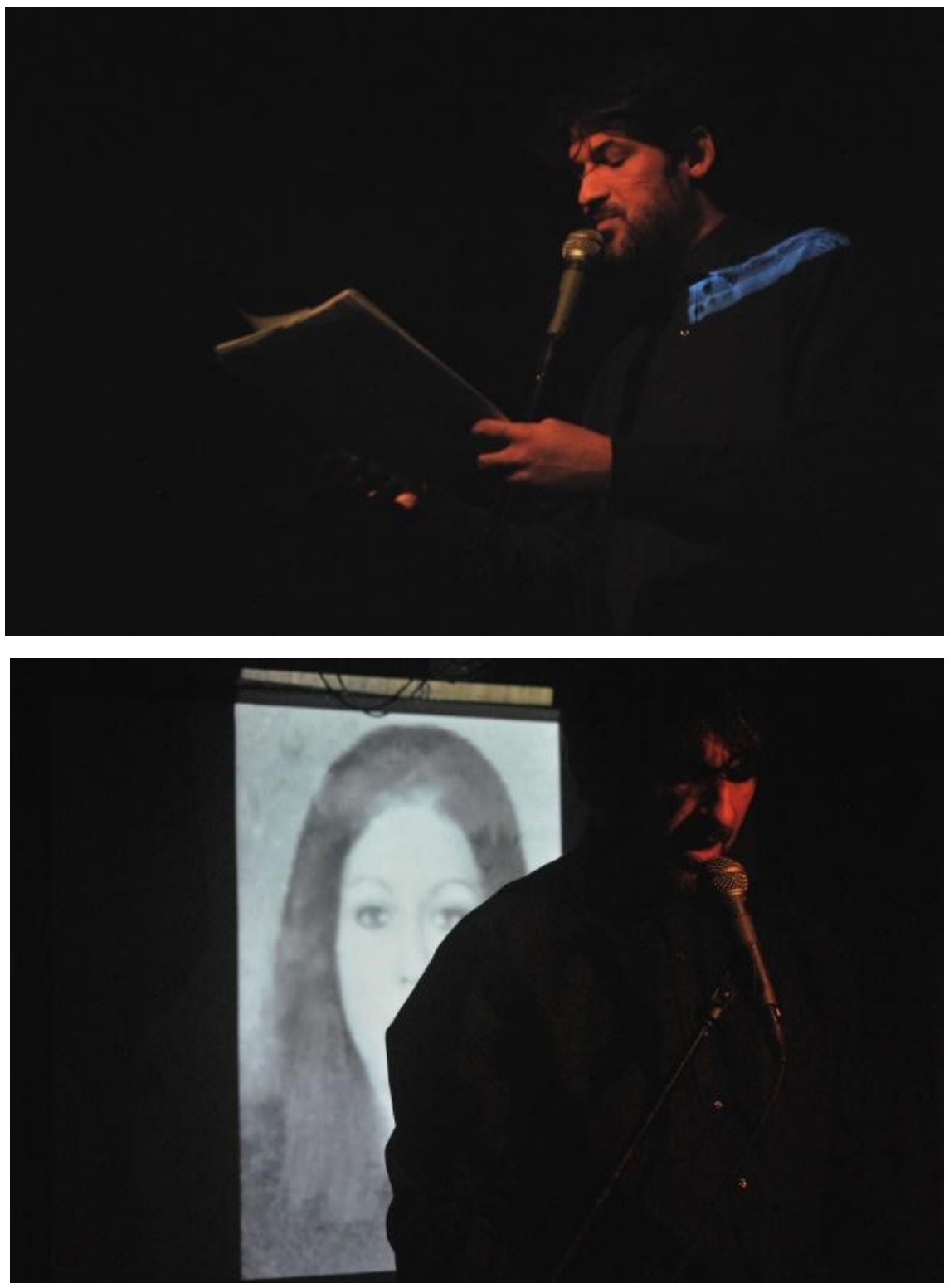

Figura 10: Ricardo Domeneck no estúdio Audio Rebel, Rio de Janeiro, numa exibição no programa Subcena. Abaixo, ele está à frente de uma foto de uma das vítimas da ditadura civil-militar (1964-1985); na performance, Domeneck diz nomes de mortos/as e desaparecidos/as políticos/as listados/as pela Comissão Nacional da Verdade, enquanto vemos suas fotografias $3 \times 4$ na projeção. A apresentação aconteceu um dia após o primeiro turno das Eleições 2018. 
Numa performance realizada na Audio Rebel, em 2018, a escolha de Domeneck de incluir no sua seleta de leituras um poema de Torquato Neto e outro de Allen Ginsberg quer nos dizer também algumas coisas sobre o trabalho de leitura. Essa aproximação, feita por um poeta especialmente dedicado à leitura pública, aponta para as aparições em cena dos arquivos que dialogam com seu discurso político. ${ }^{6}$ Especialmente naquela noite no Rio, numa performance apresentada um dia após o primeiro turno das Eleições 2018, reiterar o verso de Torquato "aqui é o fim do mundo" se traduziu na temperatura política do momento: os rumores da ditadura militar pareciam muito próximos de um retorno (pelas urnas, ironicamente), rumores estes que se efetivaram na vitória eleitoral da chapa de extrema-direita e em inúmeros momentos obscurantistas do governo Bolsonaro.

Domeneck usou sua voz para, naquele momento, requisitar a memória contida no poema de Torquato, não como uma saudação distante da resistência aos anos do Al-5, mas como uma revalidação do contexto político brasileiro dos anos 1970 que retorna no golpismo dos dias atuais: "minha culpa, meu pecado"8 insere-se então nas disposições de ódio que se organizam em redes de ataques, no dedo indicador apontado para a diversidade dos modos de vida que parece estrangulada pelo discurso unificador e autoritário alçado à grande cena do poder de Brasília. Aquele poema reaparece no som da voz, toma outra vez assento no recado refeito a um país malfadado que gira em torno de si em ciclos de terror de Estado (Cf. Zular 2019).

Nos termos que Diana Taylor (2013) expressa para sua crítica de performance, ao reafirmar o texto de "Marginália II", retomando o arquivo deste poema ao público, Domeneck assume uma posição diante de um possível repertório, na medida em que encena "a memória incorporada" (Taylor 2013: 49), ou seja, faz uso do documento para comunicá-lo em seu corpo, em sua voz, escavando pela latência do texto para devolvê-lo à circulação, à troca, ao convívio, assim, reparando com alguma atenção os momentos históricos e atuais que se encontraram ali sobrepostos.

A viabilidade da performance de mediar uma incorporação, como diz Taylor (2013), diz respeito à maneira com as quais práticas culturais são conservadas no corpo na constante reativação de suas formas pelas pessoas de uma comunidade. Essas reencenações são imprescindíveis. Não apenas reapresentam um fato, mas conseguem sensibilizá-lo. Ao reviver e reparar na sobreposição, sentimos o problema posto e a ferida aberta pela antipolítica. Outra vez nos recolocamos para o repertório das revisões forçadas e violentas.

A maneira como arquivo e repertório são articulados em uma performance pode dar a entender que Taylor (2012; 2013) propõe uma nova visão sobre os debates que buscam relacionar escrita e fala a partir de práticas rituais. No entanto, ela expõe uma compreensão do arquivo que o revela e o desafia ao mesmo tempo; quer provocar o uso do texto para pensar como seus recursos podem ser aproveitados pelas remissões construídas e reiteradas. Nesse sentido, a multi encenação pelo repertório nos mostra como a prática 
é confiada pela presença, fazendo da escrita um registro também a se inventar, um tipo de objeto o qual, revisitado pela leitura e reincorporado pela performance, assume a pluralidade de contextos em jogo (Zumthor 1997). A apreensão ficcional e a vida mesma se apertam em uma só fenda, como indica Taylor (2013: 55, grifo meu), quando diz que a tensão entre arquivo e repertório pode ser comparada à tensão entre escrita e oralidade:

A tensão entre o que denomino arquivo e repertório tem sido frequentemente construída como existente entre língua escrita e a falada. $\mathrm{O}$ arquivo contem textos escritos, mas não se limita a eles. O repertório contém performances verbais - canções, orações, discursos -, bem como práticas não verbais. A divisão entre escrito/oral, em um nível, capta a diferença entre arquivo/repertório que venho desenvolvendo nesse estudo na medida em que os meios de transmissão diferem, como acontece também com as exigências de armazenamento e disseminação. O repertório, seja em termos de expressão verbal ou não verbal, transmite ações incorporadas reais. Assim, as tradições são armazenadas no corpo, por meio de vários métodos mnemônicos, e são transmitidas "ao vivo" no aqui e agora, para uma audiência real. Formas legadas, vindas do passado, são vivenciadas como presentes.

Os arquivos são formas legadas. Nesse sentido, podemos pensar mais uma vez a leitura a partir de uma dinâmica de performance em que registros escritos se oferecem como recursos à alteração, e não apenas como uma documentação que circula seu próprio fim; como diz Taylor (2012: 161) "a performance pertence ao repertório, o texto ao arquivo". Na performance, Domeneck se valeu da voz para recolocar aqueles textos em cena, mediando seus discursos que passavam, então, a interagir na ação presente, reinserindo o texto no nosso tempo.

Seu segundo "método mnemônico" (Taylor 2013: 55), o poema "Please Master", de Ginsberg, uma longa exaltação ao prazer carnal em versos como "aperta a minha boca contra o coração do teu pau", ${ }^{9}$ um icônico hino homoafetivo de devoção e entrega, se colocou igualmente aos ecos do contexto, quando mais uma vez a desgastada associação entre homossexualidade e degeneração supôs-se recuperada pela ascensão política dos antigos gorilas da ditadura. A intolerância se percebeu ali assolapada pelo repertório gay, pela situação descrita e cantada das possibilidades do prazer homoerótico que, manifestado publicamente, conquista e marca sua dignidade enquanto descreve maneiras de gozar e, ferindo a ufania do macho brasileiro, de se submeter ao desejo.

A maneira como Domeneck trabalha os modos diferentes para contornar uma mesma acusação nos coloca diante, para além de uma visão da escrita como modo de documentar, de uma duração dos gestos. É por aí que a relação arquivo/repertório envolve o debate escrita/oralidade sem requerer uma prevalência de uma sobre a outra para balizar sua discussão, pois estamos aqui tratando de uma espécie de caligrafia tonal (Porrúa 2011). Quando Domeneck reflete e faz recomendações sobre as particularidades do seu trabalho, incentivando a manifestação da voz como parte fundamental da prática da poesia, 
indica justamente uma relação desimpedida entre a manufatura de arquivos e a reencenação do repertório para configurar um modelo criativo que não se fecha para as dinâmicas de acionamento, utilização e recriação dos gestos de escrever (Flusser 1994). Diz Domeneck (2009: s/p):

\begin{abstract}
Porque creio que os poetas-escritores ganhariam muito, se mantivessem sua atenção também voltada para estes aspectos da prática poética, assim como creio que os poetas orais e trovadores contemporâneos brasileiros ganhariam muito se atentassem mais para a textualidade de seu trabalho oral e em performance. Os escritores ganhariam, por exemplo, pois o trabalho oral é menos suscetível a um exagero de intertextualidade (ou "metástase de referências literárias", como alguns prefeririam), assim como o contato direto com seu público, apenas possível em leituras e performances, seria extremamente saudável para alguns poetas-escritores. Quanto aos poetas orais, uma maior preocupação (digamos) literária permitiria a criação de textos mais tesos, densos e concretos, que poderiam também funcionar na página.
\end{abstract}

Quando emparelhamos a sua recomendação aos enunciados de Taylor (2012; 2013), Domeneck parece admitir que o trabalho do/a poeta é feito a partir de uma intensa via em mão dupla entre arquivo e repertório, em que as dimensões da escrita e da voz permanecem em trânsito (o que significa também fabular trocas de posição), assim como são retroalimentadas, uma pela outra, em sua manifestação pública, em sua prática e em seus modos de viragem. Ele parece assim conversar com algumas das dimensões de Eletrovento, de Fabião, e d'Os bichos, de Chacal.

Diante desses eventos, não interessa tanto gastarmos linhas com marcos que conferem uma poesia monomidiática, pois dificilmente assim ela é. ${ }^{10} \mathrm{O}$ poema retorna à voz porque é feito para retornar. E por aí, também, um destino da literatura se cumpre. 


\section{NOTAS}

* Thadeus C. Santos - doutorando do PPG Literatura, Cultura e Contemporaneidade (PUC-Rio) - é assistente editorial no Grupo Editorial Record, produtor cultural do projeto Subcena (2017-2020) e um dos editores da coleção de poesia A Galope (Garupa e kza1, 2019-2021).

${ }^{1}$ Perspectivas Anos 20, conversa com Eleonora Fabião. Disponível em https://youtu.be/8dELALbpsjs. Acessado em 25/07/2021.

${ }^{2}$ Cf. Senado Federal. Relatório final da CPI da Pandemia. Brasília, 2021. Disponível em https://senadofederalmy.sharepoint.com/personal/cpipandemia_arquivos_senado_leg_br/_layouts/15/onedrive.aspx?id=\%2Fpe rsonal\%2Fcpipandemia\%5Farquivos\%5Fsenado\%5Fleg\%5Fbr\%2FDocuments\%2FRelat\%C3\%B3rio\%20Fin al\%2FRelatorio\%5FFinal\%5Faprovado\%2Epdf\&parent=\%2Fpersonal\%2Fcpipandemia\%5Farquivos\%5Fsen ado\%5Fleg\%5Fbr\%2FDocuments\%2FRelat\%C3\%B3rio\%20Final. Acessado em 13/11/2021.

${ }^{3}$ Fabião cita Preciado (2014) em tradução própria; para facilitar o estudo da performance, reproduzo aqui outra tradução, publicada no jornal $O$ povo: "Não foram o motor a vapor, a imprensa ou a guilhotina as primeiras máquinas da Revolução Industrial, mas sim o escravo trabalhador da lavoura, a trabalhadora do sexo e reprodutora, e os animais. As primeiras máquinas da Revolução Industrial foram máquinas vivas. Assim, o humanismo inventou um outro corpo que chamou humano: um corpo soberano, branco, heterossexual, saudável, seminal. Um corpo estratificado, pleno de órgãos e de capital, cujas ações são cronometradas e cujos desejos são os efeitos de uma tecnologia necropolítica do prazer. Liberdade, igualdade, fraternidade. $\mathrm{O}$ animalismo revela as raízes coloniais e patriarcais dos princípios universais do humanismo europeu. 0 regime de escravidão, e depois o regime de trabalho assalariado, aparece como o fundamento da liberdade dos 'homens modernos'; a expropriação e a segmentação da vida e do conhecimento como o reverso da igualdade; a guerra, a concorrência e a rivalidade como operadores da fraternidade." O povo, 24/11/2014. Disponível em https://www20.opovo.com.br/app/colunas/filosofiapop/2014/11/24/ noticiasfilosofiapop,3352134/ofeminismo-nao-e-um-humanismo.shtml. Acesso em 04/07/2021.

${ }^{4}$ Cf. Carlos Gomes. Poesia falada - a Subcena. Revista Continente, Recife, 2018. Disponível em https://youtu.be/ Tgl5YB6n_90. Acesso em 02/11/2021.

${ }^{5}$ Ricardo Domeneck. Garganta com texto, 2007. Disponível em https://youtu.be/sZwFos5meBU. Acesso em $14 / 08 / 2021$.

${ }^{6}$ Ricardo Domeneck, Subcena, 2018. Disponível em https://youtu.be/TWe8k2BzD9g. Acessado em 12/08/2021.

${ }^{7}$ Torquato Neto, “Marginália II”. Os últimos dias de Paupéria. São Paulo: Max Limonad, 1982, p. 432.

${ }^{8}$ Ibidem.

${ }^{9} \mathrm{Na}$ Audio Rebel, Domeneck recitou “Please Master" conforme o original em inglês. Para facilitar a leitura, utilizo aqui uma tradução de Paulo Henriques Brito divulgada pelo blog do Claudio Willer, "Por favor meu amo", apresentada espirituosamente como “Ginsberg para homofóbicos”. Disponível em https://claudiowiller. wordpress.com/2015/06/05/allen-ginsberg-para-homofobicos-um-poema-edificante-e-instrutivo/. Acessado em 17/07/2021.

${ }^{10}$ Ao comentar sobre a diferença do lugar da voz na Odisseia e na Bíblia, Roberto Zular (2019, p. 382) chama a atenção para o "lugar da literatura como um lugar de agenciamento de diferentes modos de relação entre a 


\section{BIBLIOGRAFIA}

Aleixo, Ricardo (2015), "Falhe comigo (corpografia)", Recibo 33. Disponível em https:// soundcloud.com/recibo33/ricardoaleixo2. Acesso em 05/04/2021.

Bernstein, Charles (1998), "Introduction”, in Bernstein, Charles (org.), Close Listening: Poetry and the Performed Word. Nova York: Oxford University Press, p. 3-25. A tradução de Lucas Matos está disponível em http://blissnaotembis.com/blog/2014/04/revistadisco-blliss-nao-tem-bis-escuta-critica-poesia-e-a-palavra-em-performance.html. Acesso em 24 jul. 2021.

-- (2009), "Hearing Voices", in Perloff, Marjorie/ Dworkin, Craig (orgs.), Poetry of Sound / Sound of poetry. Chicago, The University Chicago Press: 142-148.

Cavarero, Adriana (2011), Vozes plurais: filosofia da expressão vocal. Tradução de Flavio Terrigno Barbeitas, Belo Horizonte. Editora UFMG, 312 p.

Chacal, Ricardo (2017), "Trabalho", e-Lyra, n. 10: 13-25.

Coelho, Frederico (2016), "Usos da voz na canção popular - apontamentos e hipótese". Ipotese, Juiz de Fora, v. 20, n. 1: 194-203.

Domeneck, Ricardo (2019), Escrever em voz alta [série], s/p. Conjunto de três textos em blog. Escrever em voz alta: parte 1: A pergunta, disponível em http://ricardo-domeneck. blogspot.com/2009/08/escrever-em-voz-alta-parte-1.html; Escrever em voz alta: parte 2: explicando, implicando, disponível em http://ricardo-domeneck.blogspot. com/2009/08/escrever-em-voz-alta-parte-2-explicando.html; Escrever em voz alta: parte 3: meça o corpo presente, disponível em http://ricardo-domeneck.blogspot. com/2009/08/escrever-em-voz-alta-parte-3-meca-o.html. Acesso em 07 jul. 2021.

Fabião, Eleonora (2011), "Performance e precariedade”, in Oliveira Junior, Antonio Wellington de (org.), A performance ensaiada: ensaios sobre performance contemporânea. Fortaleza, Expressão: 63-86.

Flusser, Vilém (1994), Los gestos: fenomenologia y comunicación. Tradução de Claudio Gancho, Barcelona, Herder, 214 p.

Glusberg, Jorge (1986), A arte da performance. Tradução de Renato Cohen, São Paulo Perspectiva, $146 \mathrm{p}$. 
Haraway, Donna J (2016), Staying with the Trouble: Making Kin in the Chthulucene. Durham, Duke University Press, 296 p.

Porrúa, Ana María (2011), Caligrafía tonal: ensayos sobre poesía. Buenos Aires, Entropía, $380 \mathrm{p}$.

Ribeiro, Gustavo Silveira (2020), Lamber o mundo com a própria língua erótica e política em Ricardo Domeneck. Eutomia, Recife, v. 1, n. 26: 45-58.

Santos, Milton (2021), Por uma outra globalização: do pensamento único à consciência universal. Rio de Janeiro, Record, 196 p.

Simas, Luiz Antonio/ Rufino, Luiz (2020), Encantamento: sobre política de vida. Rio de Janeiro, Mórula, $41 \mathrm{p}$.

Taylor, Diana (2013), O arquivo e o repertório: performance e memória cultural nas Américas. Tradução de Eliana Lourenço de Lima Reis, Belo Horizonte, Editora UFMG, 430 p.

-- (2009), O trauma como performance de longa duração. Tradução de Giselle Ruiz, O percevejo online, Rio de Janeiro, v. 1, fasc. 1, jan.-jun.: 1-12.

-- (2012), Performance. Bogotá, Instituto Hemisfério de Performance e Política, 176 p.

Zular, Roberto (2020), "No fluxo dos recados: sobredeterminação e variações ontológicas em "O recado do morro" de Guimarães Rosa e A queda do céu de Kopenawa e Albert. Crítica Cultural” - Critic, Palhoça, v. 15, n. 1: 19-39, jan-jun 2020.

-- (2019), “O núcleo pivotante da voz”, Cadernos da Tradução, Florianópolis, v. 39: 372-402. Zumthor, Paul (1997), Introdução à poesia oral. Tradução de Jerusa Pires Ferreira, São Paulo, Educ, $321 \mathrm{p}$.

-- (2018), Performance, recepção, leitura. Tradução de Jerusa Pires Ferreira, São Paulo, Ubu, $112 \mathrm{p}$. 